\title{
The increase in health care costs associated with muscle weakness in older people without long- term illnesses in the Czech Republic: results from the Survey of Health, Ageing and Retirement in Europe (SHARE)
}

This article was published in the following Dove Press journal:

Clinical Interventions in Aging

Number of times this article has been viewed

\author{
Michal Steffl' \\ Jan Sima ${ }^{2}$ \\ Kate Shiells ${ }^{3}$ \\ Iva Holmerova ${ }^{3}$ \\ 'Department of Physiology and \\ Biochemistry, Faculty of Physical \\ Education and Sport, Charles \\ University, Prague, Czech Republic; \\ ${ }^{2}$ Department of Sport Management, \\ Faculty of Physical Education and \\ Sport, Charles University, Prague, \\ Czech Republic; ${ }^{3}$ Centre of Expertise \\ in Longevity and Long-term Care, \\ Faculty of Humanities, Charles \\ University, Prague, Czech Republic
}

Correspondence: Michal Steffl Department of Physiology and Biochemistry, Faculty of Physical Education and Sport, Charles University, José Martího 269/3I, 16252 Prague, Czech Republic

Email steffl@ftvs.cuni.cz

\begin{abstract}
Muscle weakness and associated diseases are likely to place a considerable economic burden on government health care expenditure. Therefore, our aim for this study was to estimate the direct and indirect costs associated with muscle weakness in the Czech Republic. We applied a cost-of-illness approach using data from the Survey of Health, Ageing and Retirement in Europe (SHARE). Six hundred and eighty-nine participants aged 70 years and over and without any longterm illnesses were included in our study. A generalized linear model with gamma distribution was used, and odds ratio (OR) was calculated in order to explore the effect of muscle weakness on direct and indirect costs. For both genders, muscle weakness had a statistically significant impact on direct costs $(\mathrm{OR}=2.11)$, but did not have a statistically significant impact on indirect costs $(\mathrm{OR}=1.08)$ or on total cost $(\mathrm{OR}=1.51)$. Muscle weakness had the greatest statistically significant impact on direct costs in females $(\mathrm{OR}=2.75)$. In conclusion, our study has shown that muscle weakness may lead to increased direct costs, and consequently place a burden on health care expenditure. Therefore, the results of this study could lead to greater interest in the prevention of muscle weakness among older people in the Czech Republic.
\end{abstract}

Keywords: direct cost, indirect cost, economic burden, sarcopenia, frailty

\section{Introduction}

Muscle weakness as a lack of muscle strength is a primary symptom of a variety of skeletal muscle diseases ${ }^{1}$ including frailty ${ }^{2}$ and sarcopenia, ${ }^{3,4}$ both of which have been linked to increased health care expenditure for older people. ${ }^{5-7}$ In particular, frailty and its comorbidities are associated with a greater use of hospital facilities and other health care resources. ${ }^{8}$ Muscle weakness is also a significant contributing factor for falls. ${ }^{9}$ Hospitalization following a fall frequently results in further sarcopenia, often leading to a permanent loss of independence, ${ }^{10}$ in turn generating considerable treatment costs.

Studies carried out in the USA have shown that reducing the prevalence of sarcopenia by $10 \%$ would result in savings of $\$ 1.1$ billion per year in US health care costs. ${ }^{7}$ However, in the Czech Republic, the relationship between muscle weakness and health care costs has received little attention. Appropriate interventions such as physical exercise are known to lower the risk of developing sarcopenia and frailty, as well as muscle weakness, ${ }^{11}$ and hold promise for ameliorating the financial burden associated 
with these conditions. ${ }^{12}$ Consequently, increased knowledge of the impact of muscle weakness on health care expenditure could bring support for the introduction of physical activity programs for older people in the Czech Republic. Therefore, the main aim of this study was to describe the influence of muscle weakness on health care expenditure in the Czech Republic. However, it should be noted that we have only included those participants without any long-term illnesses.

\section{Methods}

\section{Study population}

This study used data from the Survey of Health, Ageing and Retirement in Europe (SHARE) Wave 6 (DOI: 10.6103/SHARE.w6.600). ${ }^{13}$ See Börsch-Supan et al ${ }^{14}$ for methodological details. The data accessed from SHARE are available to the scientific community after registering for free. No approval from an ethics committee or an institutional review board was required. Data from 750 participants without any long-term illnesses aged $\geq 70$ from the Czech Republic were included in the study. After excluding all those with missing data in the variables which were included into the regression models, data from 689 participants were used for the analyses.

\section{Long-term illness}

The SHARE survey determined the presence of any long-term illnesses using the following question: Some people suffer from chronic or long-term health problems. By chronic or long term, we mean it has troubled you over a period of time or is likely to affect you over a period of time. Do you have any such health problems, illness, disability or infirmity?

\section{Muscle weakness}

In accordance with suggested methods, we used a grip strength (GS) test to estimate muscle weakness. ${ }^{15}$ In SHARE, the GS was measured using a handheld dynamometer (Smedley, S Dynamometer, 100 kg; TTM, Tokyo, Japan). Participants were asked to squeeze the handle of the dynamometer as hard as they could for a couple of seconds and then let go. Two alternate measurements from their right and left hands were performed. The measurement was carried out in three positions in SHARE: lying, sitting and standing. For the purposes of this study, we only used data from participants who were measured in standing and sitting positions and from those who gave full effort without the support of the other hand. The maximum value was defined as the maximum performance of the strongest hand. ${ }^{16}$ Muscle weakness was defined as low GS $<26 \mathrm{~kg}$ in men and $<16 \mathrm{~kg}$ in women. ${ }^{15}$

\section{Cost of illness}

We used a cost-of-illness approach to estimate the increase in expenditure associated with muscle weakness. This approach involved estimating the costs associated with the treatment and care of patients with any disease. The expenditure was divided into two important groups: direct and indirect costs. ${ }^{17,18}$ In this case, direct costs referred to the cost of medical care and medication. Indirect costs included the replacement cost. All figures could be obtained from the SHARE questionnaire.

Participants were asked how many times in total they had seen or talked to a medical doctor in the last year, including emergency room or outpatient clinic visits. They were then asked how many nights they had spent in hospital over the last 12 months. The average cost of hospital admission was $54.59 €$ per day, and the average cost of an ordinary visit to a medical specialist was $12.47 €$ per visit. These figures were obtained from official statistics published by the Ministry of Health in the Czech Republic. In the Czech Republic, health insurance covers the total medical-related costs incurred plus the cost of any out-of-pocket medications bought by the patient. The cost of out-of-pocket medications for patients was estimated using another question: Overall, approximately how much did you spend on your medication in the last 12 months (that is, how much did you pay without being reimbursed [by a health insurance/your national health system/a third-party payer])?

Additionally, we estimated indirect costs. In order to do so, we used a series of questions to enquire about the amount of help provided by a family member from outside the household or by any friend or neighbor. Using these questions, we were able to estimate the total time which all caregivers spent assisting participants. To estimate the replacement cost, we used the average wage of a professional caregiver in the Czech Republic (6.34€ per hour), which was obtained from the Ministry of Labour and Social Affairs.

\section{Statistical analysis}

The means and standard deviations were calculated for continuous variables, whereas frequencies and percentages were calculated for categorical variables in the descriptive statistics. Differences between sample proportions of categorical variables were tested by a $\chi^{2}$ test $(p<0.05)$. The nonparametric Mann-Whitney $U$ test $(p<0.05)$ was used to test for differences between groups according to the weakness status. A generalized linear model with gamma distribution was used to explore the effect of muscle weakness on each cost separately. All the models were adjusted for age and 
body mass index. Odds ratio (OR) was used as the main outcome of effect size in the generalized linear model. An OR value higher than 1 implies that muscle weakness caused the costs to be more expensive. All the statistical analyses were performed using IBM SPSS Statistics 22.

\section{Results}

Data from 304 men and 385 women were analyzed. The average age was 75.6 \pm 5.1 . Participants diagnosed with muscle weakness $(81.8 \pm 6.6)$ were significantly older than participants with normal muscle strength (75.2 \pm 4.8$)$. With increasing age, the prevalence of muscle weakness also increased, from $4.6 \%$ for those aged $70-74$ years old to $31.9 \%$ for participants over 85 years of age. Prevalence of muscle weakness in males was $8.6 \%$ and in females was $10.1 \%$. The descriptive statistics of the study sample are presented in Table 1.

Direct, indirect and total costs were statistically higher for the muscle weakness group compared with the normal muscle group. In all the estimates, the hospital admission had a major contribution to the direct cost because the muscle weakness group was almost a third more likely to attend hospital admission. The average total cost was estimated at $1,125.3 \pm 1,367.2 €$ for the group with muscle weakness and 561.4 $\pm 762.6 €$ per year for the normal muscle group. A summary of costs per year divided according to muscle weakness status is presented in Table 2.

Table 3 shows the results obtained from generalized linear regression models estimated separately for each type of cost. In both genders combined, muscle weakness had a statistically significant impact on direct costs $(\mathrm{OR}=2.11)$, but did not have a statistically significant impact on indirect

Table I Descriptive statistics of participants

\begin{tabular}{|c|c|c|c|c|}
\hline Variable & $\begin{array}{l}\text { All } \\
(N=689)\end{array}$ & $\begin{array}{l}\text { Muscle } \\
\text { weakness } \\
(n=65)\end{array}$ & $\begin{array}{l}\text { Normal } \\
(n=624)\end{array}$ & $p$-value ${ }^{a}$ \\
\hline Age, years & $75.6(5.1)$ & $81.8(6.6)$ & $75.2(4.8)$ & $<0.001$ \\
\hline \multicolumn{5}{|l|}{ Age categories } \\
\hline $70-74, \%$ & 54.0 & 4.6 & 95.4 & $<0.001$ \\
\hline $75-79, \%$ & 24.4 & 7.1 & 92.9 & \\
\hline $80-84, \%$ & 14.8 & 20.6 & 79.4 & \\
\hline $85+, \%$ & 6.8 & 31.9 & 68.1 & \\
\hline \multicolumn{5}{|l|}{ Sex } \\
\hline Males, \% & 44. I & 8.6 & 91.4 & 0.482 \\
\hline Females, \% & 55.9 & 10.1 & 89.9 & \\
\hline Grip strength, kg & $31.7(9.4)$ & I7.9 (4.4) & $32.4(9.1)$ & $<0.001$ \\
\hline
\end{tabular}

Notes: The values are expressed as mean (SD) for continuous data and percentage for categorical data. ${ }^{\text {PPearson }} \chi^{2}$ test for qualitative variables, Mann-Whitney $U$ test for continuous variables.
Table 2 Summary of costs per year divided according to weakness status

\begin{tabular}{|c|c|c|c|}
\hline Variable & $\begin{array}{l}\text { Muscle } \\
\text { weakness } \\
(n=65)\end{array}$ & $\begin{array}{l}\text { Normal } \\
\text { strength } \\
(n=624)\end{array}$ & P-value ${ }^{a}$ \\
\hline Direct costs, $€$ & $475.3(853.0)$ & $221.6(364.8)$ & 0.001 \\
\hline \multicolumn{4}{|l|}{ Medical care } \\
\hline Hospital admission, $€$ & $318.2(863.2)$ & $83.6(317.0)$ & $<0.001$ \\
\hline Medical visits, $€$ & $90.9(63.2)$ & $78.0(79.3)$ & 0.087 \\
\hline Medications, $€$ & $66.3(71.6)$ & $60.1(84.5)$ & 0.553 \\
\hline \multicolumn{4}{|l|}{ Indirect cost } \\
\hline Replacement cost, $€$ & $649.9(851.8)$ & $339.8(660.3)$ & 0.019 \\
\hline Total cost, $€$ & I,I $25.3(I, 367.2)$ & $561.4(762.6)$ & 0.001 \\
\hline
\end{tabular}

Notes: The values are expressed as mean (SD); a Mann-Whitney $U$ test.

costs $(\mathrm{OR}=1.08)$ or total cost $(\mathrm{OR}=1.51)$. In males, muscle weakness did not have a statistically significant impact on any of the costs. The highest statistically significant impact was found to be the impact of muscle weakness on direct costs in females $(\mathrm{OR}=2.75)$.

\section{Discussion}

According to our results, muscle weakness may influence health care expenditure for elderly people in the Czech Republic who are relatively healthy and do not have any long-term illnesses. In the context of previous studies, these results are not unexpected. Several diseases which are connected with the musculoskeletal system have previously been found to increase health care expenditure. For example, Bock et $\mathrm{l}^{6}$ found that frailty is associated with increased health care costs among older Germans. Furthermore, frailty was shown to increase surgical hospital costs after colorectal operations in American older adults. ${ }^{19}$ In Ireland, a strong association between frailty and daily informal care costs was found, ${ }^{20}$ and in the Netherlands, one study showed increased health care costs among frail elderly persons. ${ }^{21}$ In the USA, sarcopenia has placed a significant economic burden on governmentreimbursed health care services. ${ }^{7}$ Also, similar to frailty and sarcopenia, osteoporosis has had a high impact on state

Table 3 Generalized linear regression model for weak individuals

\begin{tabular}{llll}
\hline Model & $\begin{array}{l}\text { Direct cost OR } \\
(\mathbf{9 5 \%} \text { Wald CI) }\end{array}$ & $\begin{array}{l}\text { Indirect cost OR } \\
(\mathbf{9 5 \%} \text { Wald CI) }\end{array}$ & $\begin{array}{l}\text { Total cost OR } \\
\mathbf{( 9 5 \% ~ W a l d ~ C I ) ~}\end{array}$ \\
\hline Both genders & 2.106 & 1.080 & 1.510 \\
combined & $(1.434-3.092) *$ & $(0.763-1.529)$ & $(0.972-2.346)$ \\
Males & 1.426 & 1.033 & 1.312 \\
& $(0.803-2.533)$ & $(0.605-1.764)$ & $(0.684-2.5 I 7)$ \\
Females & 2.747 & $1.05 I$ & 1.582 \\
& $(1.643-4.593)^{*}$ & $(0.673-1.64 I)$ & $(0.875-2.86 I)$ \\
\hline
\end{tabular}

Notes: Models were adjusted for age and BMI; statistical significance $*_{p}<0.05$ Abbreviations: BMI, body mass index; OR, odds ratio. 
medical budgets in the USA, ${ }^{22}$ as well as in Switzerland ${ }^{23}$ and Germany. ${ }^{24}$ In the Czech Republic, a report by the Organization for Economic Co-operation and Development states that diseases of the musculoskeletal system are one of the five most burdensome disease groups in the country. ${ }^{25}$ Moreover, reduced handgrip strength alone has been identified as a predictor of hospitalization costs. ${ }^{26}$

Although our results reflect those found in previous research carried out in the field, several limitations of our study should be taken into account. Firstly, the data were extracted from a sociological survey based on a questionnaire. Therefore, the subjectivity of responses may have altered their meanings. Even though handgrip strength was measured by a standard dynamometer, the technique was not fully in line with the recommendations for medical research. The SHARE sample also contained a small proportion of people who were classified as weak compared to those who had normal muscle strength. Moreover, participants in the muscle weakness group were older than those in the normal strength group. This may have skewed our results. Undoubtedly, estimating direct and indirect costs using economic data could produce more accurate results; unfortunately, such a study has not been done in the Czech Republic.

According to our results, muscle weakness has a significant impact on health care expenditure, specifically in relation to direct costs. Therefore, despite the potential limitations of this study, it is important to consider appropriate interventions that can be introduced to lower the risk of muscle weakness, which can in turn reduce associated health care expenditure. Physical activity has previously been identified as an appropriate intervention for decreasing the risk of muscle weakness. ${ }^{27}$ Therefore, interventions involving physical activity may be associated with cost saving. In this context, the results of our study should lead to increased interest in the implementation of physical activity programs for the elderly.

\section{Acknowledgments}

The SHARE data collection has been primarily funded by the European Commission through FP5 (QLK6-CT-2001-00360), FP6 (SHARE-I3: RII-CT-2006-062193, COMPARE: CIT5CT-2005-028857, SHARELIFE: CIT4-CT-2006-028812) and FP7 (SHARE-PREP: N²11909, SHARE-LEAP: N²27822, SHARE M4: N²61982). Additional funding from the German Ministry of Education and Research, the US National Institute on Aging (U01_AG09740-13S2, P01_AG005842, P01_AG08291, P30_AG12815, R21_AG025169, Y1-AG4553-01, IAG_BSR06-11, OGHA_04-064) and from various national funding sources is gratefully acknowledged (see www.share-project.org).

This publication was supported by the AZV research projects 16-29182A and 15-32942A of the Ministry of Health and projects Q 41 and Q 19.

\section{Disclosure}

The authors report no conflicts of interest in this work.

\section{References}

1. Marx J, Hockberger R, Walls R. Rosen's Emergency Medicine Concepts and Clinical Practice. Philadelphia: Mosby/Elsevier; 2014.

2. Bandeen-Roche K, Xue QL, Ferrucci L, et al. Phenotype of frailty: characterization in the women's health and aging studies. J Gerontol A Biol Sci Med Sci. 2006;61(3):262-266.

3. Fielding RA, Vellas B, Evans WJ, et al. Sarcopenia: an undiagnosed condition in older adults. Current consensus definition: prevalence, etiology, and consequences. International working group on sarcopenia. J Am Med Dir Assoc. 2011;12(4):249-256.

4. Cruz-Jentoft AJ, Baeyens JP, Bauer JM, et al; European Working Group on Sarcopenia in Older People. Sarcopenia: European consensus on definition and diagnosis: Report of the European Working Group on Sarcopenia in Older People. Age Ageing. 2010;39(4):412-423.

5. Comans TA, Peel NM, Hubbard RE, Mulligan AD, Gray LC, ScuffhamPA. The increase in healthcare costs associated with frailty in older people discharged to a post-acute transition care program. Age Ageing. 2016; 45(2):317-320.

6. Bock JO, Konig HH, Brenner H, et al. Associations of frailty with health care costs results of the ESTHER cohort study. BMC Health Serv Res. 2016;16:128.

7. Janssen I, Shepard DS, Katzmarzyk PT, Roubenoff R. The healthcare costs of sarcopenia in the United States. J Am Geriatr Soc. 2004; 52(1):80-85.

8. García-Nogueras I, Aranda-Reneo I, Peña-Longobardo LM, OlivaMoreno J, Abizanda P. Use of health resources and healthcare costs associated with frailty: the FRADEA study. J Nutr Health Aging. 2017; 21(2):207-214.

9. Morley JE, Anker SD, von Haehling S. Prevalence, incidence, and clinical impact of sarcopenia: facts, numbers, and epidemiology-update 2014. J Cachexia Sarcopenia Muscle. 2014;5(4):253-259.

10. Landi F, Cruz-Jentoft AJ, Liperoti R, et al. Sarcopenia and mortality risk in frail older persons aged 80 years and older: results from ilSIRENTE study. Age Ageing. 2013;42(2):203-209.

11. Borst SE. Interventions for sarcopenia and muscle weakness in older people. Age Ageing. 2004;33(6):548-555.

12. Fried TR, Bradley EH, Williams CS, Tinetti ME. Functional disability and health care expenditures for older persons. Arch Intern Med. 2001; 161(21):2602-2607.

13. Börsch-Supan A. Survey of Health, Ageing and Retirement in Europe (SHARE) Wave 6. Release version: 6.0.0. SHARE-ERIC. Data set. (2017). DOI: 10.6103/SHARE.w6.600.

14. Börsch-Supan A, Brandt M, Hunkler C, et al; SHARE Central Coordination Team. Data resource profile: the Survey of Health, Ageing and Retirement in Europe (SHARE). Int J Epidemiol. 2013;42(4):992-1001.

15. McLean RR, Shardell MD, Alley DE, et al. Criteria for clinically relevant weakness and low lean mass and their longitudinal association with incident mobility impairment and mortality: the foundation for the National Institutes of Health (FNIH) sarcopenia project. J Gerontol A Biol Sci Med Sci. 2014;69(5):576-583.

16. Andersen-Ranberg K, Petersen I, Frederiksen H, Mackenbach JP, Christensen K. Cross-national differences in grip strength among 50+ year-old Europeans: results from the SHARE study. Eur J Ageing. 2009;6(3):227-236. 
17. Jo C. Cost-of-illness studies: concepts, scopes, and methods. Clin Mol Hepatol. 2014;20(4):327-337.

18. Clabaugh G, Ward MM. Cost-of-illness studies in the United States: a systematic review of methodologies used for direct cost. Value Health. 2008;11(1):13-21.

19. Robinson TN, Wu DS, Stiegmann GV, Moss M. Frailty predicts increased hospital and six-month healthcare cost following colorectal surgery in older adults. Am J Surg. 2011;202(5):511-514.

20. Butler A, Gallagher D, Gillespie P, et al. Frailty: a costly phenomenon in caring for elders with cognitive impairment. Int J Geriatr Psychiatry. 2016;31(2):161-168

21. Peters LL, Burgerhof JG, Boter H, Wild B, Buskens E, Slaets JP. Predictive validity of a frailty measure (GFI) and a case complexity measure (IM-E-SA) on healthcare costs in an elderly population. $J$ Psychosom Res. 2015;79(5):404-411.

22. Rousculp MD, Long SR, Wang S, Schoenfeld MJ, Meadows ES. Economic burden of osteoporosis-related fractures in Medicaid. Value Health. 2007;10(2):144-152.
23. Svedbom A, Ivergard M, Hernlund E, Rizzoli R, Kanis JA. Epidemiology and economic burden of osteoporosis in Switzerland. Arch Osteoporos. 2014;9:187.

24. Bleibler F, Konnopka A, Benzinger P, Rapp K, Konig HH. The health burden and costs of incident fractures attributable to osteoporosis from 2010 to 2050 in Germany a demographic simulation model. Osteoporos Int. 2013;24(3):835-847.

25. OECD. "Expenditure by disease and age". Health at a Glance 2015: OECD Indicators. Paris: OECD Publishing; 2015.

26. Guerra RS, Amaral TF, Sousa AS, et al. Handgrip strength measurement as a predictor of hospitalization costs. Eur J Clin Nutr. 2015;69(2): 187-192.

27. Steffl M, Bohannon RW, Sontakova L, Tufano JJ, Shiells K, Holmerova I. Relationship between sarcopenia and physical activity in older people: a systematic review and meta-analysis. Clin Interv Aging. 2017;12: $835-845$.
Clinical Interventions in Aging

\section{Publish your work in this journal}

Clinical Interventions in Aging is an international, peer-reviewed journal focusing on evidence-based reports on the value or lack thereof of treatments intended to prevent or delay the onset of maladaptive correlates of aging in human beings. This journal is indexed on PubMed Central, MedLine,

\section{Dovepress}

CAS, Scopus and the Elsevier Bibliographic databases. The manuscript management system is completely online and includes a very quick and fair peer-review system, which is all easy to use. Visit http://www.dovepress. com/testimonials.php to read real quotes from published authors. 